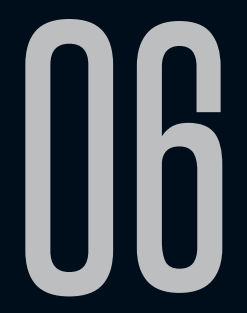

\title{
O INTRUSO, DE H. P. LOVECRAFT: O UNHEIMLICH NO ESPELHO
}

\author{
Ramiro Giroldo (UFMS/CNPq) \\ Carla Larissa dos Santos de Souza (UFMS)
}

Recebido em 22 jun 2019. Ramiro Giroldo é Doutor em Letras pela USP, Professor Aprovado em 27 ago 2019. Adjunto da UFMS e Pesquisador do CNPq, atuando na Graduação e na Pós-Graduação. Autor do livro Ditadura do prazer: sobre ficção científica e utopia e, dentre outros, dos seguintes textos publicados em periódicos científicos: "A ficção científica de Rachel de Queiroz" e "Utopia em movimento: Harmonia, de Roberto de Sousa Causo". Publicou, também, um estudo de fôlego sobre a obra de André Carneiro, "André Carneiro nos quânticos da incerteza", incluído na antologia de contos $O$ teorema das letras, do referido autor. Tem como áreas de interesse a ficção científica, o horror e a representação da violência nas artes. Lattes: http://lattes.cnpq.br/0575575502794201. E-mail: r_giroldo@yahoo.com.br

Carla Larissa dos Santos de Souza é Mestranda em Estudos de Linguagens na UFMS, Graduada em Letras na mesma instituição. Lattes: http://lattes.cnpq. br/2959522609359781. E-mail: souza.Iscarla@gmail.com

Resumo: Este texto toma como objeto o conto "O intruso", de H. P. Lovecraft e tem como objetivo a leitura do personagem que dá nome ao título como uma peculiar figura do unheimlich, que só compreende 
a sua natureza no confronto com o outro. Embasase em noções formuladas por Sigmund Freud em "O inquietante" e, também, em formulações de Noel Carroll acerca do monstro, em A filosofia do horror ou os paradoxos do coração. O texto contempla, ainda, o olhar cunhado por Lovecraft na obra $O$ horror sobrenatural na literatura. A articulação aqui apresentada busca discutir como a ambientação gótica e a atmosfera dela decorrente se relacionam no conto com o efeito unheimlich, bem como o jogo ficcional travado entre o familiar e o desconhecido.

Palavras-chave: H. P. Lovecraft; The outsider, Unheimlich; Gótico.

Abstract: This paper discusses the short-story "The outsider", by H. P. Lovecraft, and takes the titlecharacter as an peculiar example of the unheimlich, one that only understands his nature in the contact with the other. The paper is embased in notions formulated by Sigmund Freud in "O inquietante" and also in Noel Carroll's formulations on the monster, in his work $A$ filosofia do horror ou os paradoxos do coração. The paper also contemplates notions coined by Lovecraft in his work $\mathrm{O}$ horror sobrenatural na literatura. The discussion tries to analyze how the gothic setting and its atmosphere are related in the short-story with the unheimlich effect, as well as the fictional exchange between the familiar and the unknown.

Keywords: H. P. Lovecraft; The outsider, Unheimlich; Gothic.

- Por que você está usando essa fantasia estupida de coelhinho?

- Por que você está usando essa fantasia estupida de homem?

Donnie Darko 
Para Lovecraft (1987, p.1), a "emoção mais forte e mais antiga do homem é o medo; e a espécie mais forte e mais antiga de medo é o medo do desconhecido". De acordo com tal noção, o que o mundo guarda de segredos e mistérios, bem como todas as coisas que ainda não foram cognitivamente classificadas, seriam para nós as maiores fontes de medo e, paradoxalmente, do fascínio movido pela curiosidade. Seres que desafiam os parâmetros da categorização humana podem causar o efeito de repulsa, espanto ou estranhamento, de acordo com a singularidade de suas características. Articula-se à formulação de Lovecraft a recorrência em narrativas de horror de criaturas com biologias que escapam às taxionomias sistematizadas - como o ser que dá nome ao conto aqui em pauta.

Noel Carroll, em sua obra A filosofia do horror ou Paradoxos do coração, investiga a estrutura das narrativas do gênero, bem como as criaturas que as habitam. Suas proposições podem servir como um ponto de partida para discutir a natureza da criatura do conto "O intruso" (The outsider, no original) ${ }^{1}$. Nele, afinal, a criatura rompe

$$
\begin{aligned}
& \text { distinções categóricas como dentro/fora, vivo/ } \\
& \text { morto, inseto/humano, corpo/maquina, e assim } \\
& \text { por diante. [...] [Essa] figura de fusão é um composto } \\
& \text { que une atributos considerados categoricamente } \\
& \text { distintos e/ou discordantes do esquema cultural } \\
& \text { das coisas, de modo não-ambíguo, numa entidade } \\
& \text { espaço temporal discreta. (CARROLL, 1999, p.64) }
\end{aligned}
$$

De "modo não-ambíguo", ou seja, desvendada a natureza do intruso, não restam dúvidas, tanto para os demais personagens do conto, quanto para o leitor, de que seus atributos diferem radicalmente do esquema cultural em vigência. 
Recorrente na produção de Lovecraft é a maneira com que são representados esses seres transgressores: geralmente eles podem ser chamados de "coisas", pela dificuldade em encaixá-los dentro de uma categoria pré-existente. Podem ser assim chamados, portanto, devido à incapacidade humana de compreendê-los. Essa carência de parâmetros classificatórios para compreender aquilo que é até então desconhecido leva à impossibilidade de nomear e mesmo de descrever de maneira sistemática o ser, o que evidencia a pequenez humana diante dos mistérios do cosmo - nele haveria muitas coisas que escapam à nossa compreensão e, até, percepção.

O conto "O intruso" é narrado pelo seu próprio protagonista, o único personagem que ocupa algum destaque. Nem por isso, contudo, é bem delimitado: sua natureza, condição e história pessoal são bastante obscuras, portadoras de mistérios até para ele mesmo. É, dessa forma, desconhecido por si próprio - suas próprias características de contornos indefinidos (inomináveis?) são passíveis de despertar aquele maior e mais ancestral medo, o medo do desconhecido.

O texto é estruturado em duas partes: a primeira possui como ambientação o estranho lugar onde o intruso passou a maior parte de seu tempo; e a segunda é ambientada no lugar onde o segredo acerca de sua própria natureza é revelado. No primeiro momento são apresentados os rudimentos introdutórios acerca do personagem; no segundo, o conflito introduzido caminha para uma resolução.

É através do deslocamento espacial de um ambiente a outro que o personagem tem a oportunidade de conhecer a si próprio, como se compreender o contexto dos arredores contribuísse para o autoconhecimento. Restringir-se a apenas um lugar não permitiria 
o entendimento do mundo e de seu lugar nele, de acordo com a perspectiva configurada pelo conto.

O narrador conta sua história: analogamente à escuridão que até então é tudo o que ele conhece, suas memórias são também imersas nas sombras: vagas e de muito difícil apreensão. Não se lembra de sua origem, e apenas conhece sua existência dentro do castelo em que reside. Leva uma vida extremamente solitária no castelo escuro, no qual tem contato somente com "silenciosos ratos, morcegos e aranhas" (LOVECRAFT, 2017, p.299), e com a inefável criatura que o alimenta. Acerca desta, ele nada sabe com certeza, mas acredita ser um velho, devido ao aspecto curvado de seu corpo e sua pele enrugada - ainda que sua única noção de ser humano fosse constituída por meio do que leu em livros antigos armazenados em uma parte do castelo. Neste ponto, cabe dar palavra ao texto, para que a paráfrase não substitua o contato com a prosa de Lovecraft, tão capaz de criar uma atmosfera tétrica onde a decadência é a única constante. Diz o narrador:

Não sei nada do local onde nasci, exceto que era um castelo infinitamente velho e infinitamente horrível; cheio de passagens escuras e dotado de altos tetos, onde o olhar só encontrava teias de aranha e sombras. As pedras nos corredores em desagregação pareciam sempre abominavelmente úmidas, e havia um odor detestável por toda parte, como se exalasse dos cadáveres empilhados de gerações defuntas. Nunca havia claridade e por isso as vezes eu costumava ascender velas e olhalas fixamente em busca de alívio; tampouco havia algum sol do lado de fora, uma vez que as arvores terríveis cresciam muito além da mais alta torre a que se podia ter acesso. (LOVECRAFT, 2017, p.299) 
A presença do castelo e das ruínas, a descrição do ambiente com predominância de uma atmosfera escura com passagens secretas e com o enredo marcado por segredos que afetam o protagonista, remontam aspectos da literatura gótica e estimulam o leitor a jogar com seus temas - como, por exemplo, segredos do passado, manuscritos escondidos, profecias, maldições, imaginário sobrenatural, e a tentativa de despertar no leitor um efeito de horror.

Recorramos novamente às reflexões de Lovecraft, não para usá-las como uma chave interpretativa, o que impediria o devido afastamento necessário à atividade teórico-crítica, mas para compreender segundo quais parâmetros o gótico é compreendido pelo autor. Em outras palavras, o interesse é verificar de que maneira características e valores do gótico colocados em relevo em sua atividade reflexiva se veem transfigurados e/ou adotados em sua obra ficcional. Em suas palavras:

A nova parafernália dramática consistia em primeiro lugar do castelo gótico, com sua lúgubre vetustez, vastas distancias e labirintos, alas abandonadas ou em ruinas, corredores úmidos, catacumbas malsãs escondidas e uma procissão de fantasmas e de lendas tenebrosas, como núcleo de suspense e demonismo assustador. [...] toda uma série de artifícios teatrais, entre os quais estranhas luminosidades, alçapões apodrecidos, lâmpadas que não apagam manuscritos bolorentos escondidos... (LOVECRAFT, 1987, p.15-16)

Tal "parafernália" é de fato presente no conto, bem como a atmosfera por ela produzida. Além disso, cabe colocar em relevo que o conto pode ser lido como uma expressão do horror cósmico 
que é capaz de promover no leitor o efeito unheimlich. O horror cósmico seria, ainda de acordo com Lovecraft, aquela variedade do gênero que coloca os personagens diante de forças muito acima da escala humana, e distantes até mesmo de nossa capacidade de entendimento, tamanha sua dimensão. A pequenez do homem e sua insignificância no esquema geral do cosmo, assim, seria colocada em primeiro plano - sendo esta a principal fonte do efeito de horror em obras do tipo. Quanto ao unheimlich, tratemos adiante com maior vagar.

O conto promove uma inversão que só é revelada em seu desfecho. Geralmente, a criatura do horror responsável por colocar em xeque nossos parâmetros classificatórios e nossa percepção do mundo é vista pelo homem, no qual é fixado o foco narrativo. No conto, parte-se do sobrenatural para o real: o foco narrativo está na criatura hedionda. Ainda que a revelação só se dê no desfecho, toda a narrativa é revestida de um certo estranhamento, por obra da inversão. Por exemplo: o narrador evoca aspectos repulsivos que para ele são elementos normais. O trecho abaixo é um dos possíveis exemplos disseminados pela narrativa como um todo:

Para mim não havia nada de grotesco nos ossos e esqueletos que se espargiam por algumas das criptas de pedra encravadas profundamente entre as fundações. Fantasticamente, eu associava tais coisas a eventos do dia a dia, e julgava-as mais naturais do que as doloridas representações de seres vivos que encontrei em muitos dos livros bolorentos. (LOVECRAFT, 2017, p.299)

Em outra passagem, bastante ilustrativa da inversão no ponto de vista, o narrador atribui ao outro a condição de estranho: "e, 
no entanto, sinto-me estranhamente satisfeito, e agarro-me desesperadamente a essas lembranças ressequidas sempre que minha mente por um momento ameaça transcender-se até o outro" (LOVECRAFT, 2017, p.299, grifo do autor). Ele se resguarda, assim, do contato com o que é diferente, privando-se da oportunidade de enxergar-se como o outro o veria e, em última instância, de conhecer a si próprio de uma maneira que não seja estritamente restrita ao que ele conhece.

Recluso e afastado do mundo exterior, o narrador já é introduzido ao leitor, de certa forma, com traços unheimlich. Uma das definições do conceito, afinal, é a do "oculto, mantido as escondidas, de modo que os outros nada saibam a respeito" (FREUD, 2010, p.335). A reclusão em que vive é tamanha que sequer a luz do sol faz parte de sua vivência. A luz que ilumina e revela as coisas em todos os detalhes não existe em seu mundo; há no máximo a tremeluzente luz das velas, que projeta sombras móveis em cada objeto. De resto, somente há a escuridão densa que não permite enxergar nem os contornos das coisas.

Além disso, a maneira como o narrador se refere ao outro, que é o seu duplo, reforça aspectos unheimlich, "algo assustador, justamente por não ser conhecido ou familiar" (FREUD, 2010, p.331). Outro reforço de tal aspecto é a localização do castelo: ao remontar todo o trajeto feito pelo narrador, é possível perceber o local dentro do vale da estranheza. Nota-se uma constante escalada, configurando o espaço onde habita como muito abaixo do plano terreno. Levando em conta as considerações de Gaston Bachelard acerca da construção do espaço, "[...] o porão, [...] é em primeiro lugar o ser obscuro da casa, o ser que participa das 
potências subterrâneas [...] no porão há escuridão dia e noite" (BACHELARD, 1978, p.208-209). A obscuridade de sua habitação potencializa a possibilidade do insólito, assim, ao mesmo tempo em que oculta a natureza da criatura, deixa pistas nebulosas de sua identidade, detalhando as condições de subsistência que pressupõem um distanciamento do humano. Esses elementos - a forma como a atmosfera do conto é construída, o castelo, a condição do personagem - coincidem com a literatura gótica e seus desdobramentos, situando "O intruso" como uma história sobre a busca da identidade via unheimlich.

Nota-se pela descrição dos hábitos do narrador que há um aspecto duplo. Ainda que busque a luz, quando o desejo é alcançado não demonstra felicidade; ainda que tenha muito conhecimento sobre o humano e perceba-se como um, não sente o grotesco do local onde vive. A "infamiliaridade" é inspirada por costumes humanos, a familiaridade é relacionada a ossos, esqueletos e criptas de pedra. Em "O intruso", o unheimlich é constitutivo do exterior e do interior do personagem, indissociável de ambos.

O grande enigma do conto é solucionado apenas no fim do relato do protagonista, o que revela a estratégia - consciente ou não - do narrador. O espaço é descrito com detalhes, o que chama a atenção do leitor para o ambiente e desvia o foco do sujeito, mantendo-o algo incólume de toda a contaminação do ambiente que evoca a morte e a degradação.

O ambiente também representa um reflexo dos conflitos vividos pelo narrador, na primeira parte do conto. Destaca, ainda, a condição de estrangeiro do personagem, estabelecendo uma 
espécie de conflito com ele na segunda parte do conto, com a saída do subterrâneo e o revelador encontro com o outro, o ser humano. Entretanto, apesar de o narrador ser uma criatura monstruosa, ele não se vê como tal. Isso estabelece a presença do duplo em sua própria constituição, uma espécie de Dr. Jekyll que por conta própria não pode se ver como tal - apenas no contato com o outro é que tal revelação vai acontecer.

Desejando ver a luz do sol, que conhecia de descrições esparsas encontradas em livros empoeirados, o narrador tenta escapar do castelo escuro por meio de uma subida numa torre. Sabe que a tentativa pode ser frustrada e conduzi-lo à morte, mas ainda assim insiste: "melhor seria entrever o céu e perecer, que viver sem jamais contemplar o dia" (LOVECRAFT, 2017, p.300). Embora o narrador diga buscar a luz, todas as vezes em que ele tem esse contato a experiência é terrível e assustadora.

Os conflitos apresentam traços contraditórios do protagonista, como se ele buscasse mascarar através do recalque e da fuga algo que pudesse o levar ao autoconhecimento. Dessa forma, mesmo que seus aspectos físicos não tenham sido revelados, o espaço é colocado como um espelho de sua natureza. De acordo com Carroll,

Muitas vezes, o horror das criaturas horrendas não é algo que pode ser percebido a olho nu ou que aparece na descrição da aparência do monstro. Com frequência, em tais casos, o ser horrendo é rodeado de objetos que tomamos previamente como objetos de repulsa e/ou fobia. (1999, p.73)

Portanto, um ser que vive em um ambiente assustador e encontra conforto nesse lugar é provavelmente tão temível quanto 
o próprio ambiente - o castelo degradado, no caso. Podemos então considerar que, por meio da ambientação, Lovecraft propõe a reflexão acerca da composição real do personagem. Só pode viver em um ambiente assustador e tomado pela profundidade do tempo um ser que igualmente seja tão horrendo quanto o espaço que habita.

Ainda que a revelação da natureza do narrador seja exposta explicitamente somente na última linha do conto, ele deixa escapar indicações dela, seja por meio de certa reminiscência presente em alguns pontos ou nas necessidades impostas para conclusão de seu desejo de ver a luz. Explicamos: sua capacidade de escalada por uma torre lisa e em ruínas, a abertura de um alçapão de pedra até então irremovível -, a recuperação da exaustão rapidamente e, após tais feitos, atravessar a nado um rio, são exemplos reveladores de sua natureza não-humana.

Mesmo que o personagem afirme não saber nada sobre si mesmo, ele recalca ideias que o levam a ver sua natureza. Assim, entra em confronto um eu idealizado e um eu realizado. Quando o duplo age, o narrador busca abafar esse sujeito real e transfere a razão de sua condição para o castelo. Isso se estrutura na relação entre luz e escuridão, na qual a busca pela luz pode ser compreendida como a esperança do personagem. Isso pode ser observado nas seguintes passagens do conto:

Uma vez eu tentei escapar daquela mata, mas à medida que me distanciava do castelo, a penumbra se tornava cada vez mais densa e o ar mais tomado de um terror taciturno; por isso voltei correndo em desvario, antes que me perdesse em um labirinto de silencio trevoso. (LOVECRAFT, 2017, p.299) 
Quando fiz isso, desceu sobre mim o mais puro êxtase que jamais conheci, pois ali, derramando placidamente o seu brilho, através de um gradil de ferro ornado por uma curta passagem com degraus de pedra que se iniciavam na porta recém descoberta, estava a lua, que jamais vira a não ser em sonhos e em vagas visões que não ousava chamar de lembranças. (LOVECRAFT, 2017, p.301)

Após essas reações, pode-se considerar que o que o narrador procurava não era ver a luz natural, mas a cor da obscuridade por meio de uma luz construída. A única verdade que lhe era atraente era a sua. Assim, o objeto, a vela, toca o sujeito e não o sujeito toca o mundo.

Os adjetivos usados para descrever os sentimentos do personagem no encontro com a lua remetem à condição de nãopertencimento àquele mundo. Ao invés de sentir-se feliz com o êxito de sua escalada e com o encontro com o mundo fora do castelo, a surpresa de encontrar-se em um plano terreno quebra as expectativas do personagem e indica sua condição de alheio àquele universo. Afinal, ele vivia no subterrâneo sem sabê-lo, em profunda alienação do mundo. Ao colocar o leitor na mesma condição do personagem, é potencializado o efeito de horror; porém, neste momento o leitor é levado a cogitar, mais que a natureza do esperançoso personagem, qual será o possível desfecho de sua busca. Assim, resta ao narrador a agonia de conhecer seu duplo sozinho, aumentando sua condição de solidão.

O clímax da narrativa é iniciado quando o narrador, ainda tomado de certa esperança, desbrava o mundo além dos muros de seu espaço procurando por companhia humana. Após um longo 
percurso, já mencionado acima, ele acaba por encontrar o que buscava - apenas para descobrir seus equívocos. Ao avistar "um castelo coberto de heras em um parque densamente arborizado; insanamente familiar, ainda que pleno de desconcertante estranheza" (LOVECRAFT, 2017, p.301), ele pode observar janelas abertas, repletas irradiando luz e "o som da mais alegre festividade" (LOVECRAFT, 2017, p.301).

Novamente, os adjetivos evocados pelo narrador remontam ao outro como estranho, anunciando sua entrada no tão ansiado, assustador e estranho momento. Também essa cena, relembra aspectos do conto The Masque of the Red Death, de Edgar Allan Poe, quando a morte escarlate entra no salão do baile; de início o mascarado não é visto com tanto temor, entretanto, após a retirada de seu traje é revelada a sua verdadeira natureza e os convidados são tomados por um terror inominável. Diferente dele, "O intruso" não possui uma máscara exterior, mas sua condição dupla, fortificada pela falta de espelhos na antiga morada e o recalque das lembranças, constroem na mente do sujeito uma máscara ilusória, que só existe em sua mente. A máscara e o espelho assumem condição semelhante da encontrada no texto El espejo, de Jorge Luis Borges, no qual ele adverte "[...] yo temo ahora que el espejo encierre / El verdadero rostro de mi alma, / Lastimada de sombras y de culpas, / El que dios ve e acaso ven los hombres" (BORGES, 1989, p.193). Assim como no conto, o espelho assume o papel de ruptura e revelação, objeto de terror e fascínio para os sujeitos duplos.

Após entrar no salão, o personagem passa de seu "único momento de radiante esperança à mais sombria convulsão de desespero e desilusão que já sentira" (LOVECRAFT, 2017, p.302). 
A reação das pessoas deixa o narrador confuso e, mais uma vez, sozinho; em seguida, a presença de um ser monstruoso o deixa atordoado, provocando o mais profundo sentimento de horror.

O pesadelo começou rápido, pois, enquanto eu entrava, imediatamente ocorreu uma das mais aterrorizantes demonstrações que jamais concebi. Mal havia cruzado o parapeito quando, sobre todo o grupo abateu-se um pavor repentino e inesperado de intensidade assustadora, distorcendo cada face e extraindo os gritos mais horríveis de quase todas as gargantas. A fuga foi geral, e em meio ao clamor do pânico, vários perderam os sentidos e foram arrastados por seus acompanhantes em demencial debandada. [...] tremi ao pensar o que poderia estar à espreita junto a mim sem que eu o visse. [...] e então, com o primeiro e último som que jamais pronunciei - um ulular horripilante que me revoltou com quase tanta pungência quanto sua perniciosa causa -, contemplei em sua plena e assustadora nitidez a monstruosidade inconcebível, indescritivel e inefável que com sua simples aparição transformara um grupo festivo numa horda de fugitivos delirantes. (LOVECRAFT, 2017, p.302)

A reação do narrador, embora colocada com total adequação em relação ao encontro com o monstruoso, remonta um aspecto intrigante, o ulular. Esse som demonstra a presença da manifestação do seu duplo agindo sobre o ser; o ulular, selvagem e triste, aponta para a possível consciência de sua condição juntamente com a destruição de quase toda a sua esperança.

Em seguida, o ser confrontado é descrito da seguinte forma:

Não posso dar se quer uma ideia de seu aspecto, pois era uma combinação de tudo o que é poluto, nefasto, indesejável, anormal e detestável. Era a 
imagem macabra da decomposição, da antiguidade e da desolação. O pútrido e viscoso eidolon de uma revelação doentia; o desnudamento daquilo que a terra misericordiosa deveria para sempre ocultar. Deus sabe que aquilo não era desse mundo - ou não mais desse mundo -, no entanto, para meu horror, vi nos seus traços carcomidos e de ossos expostos um arremedo perverso e repugnante da forma humana; e em suas vestes bolorentas e em desintegração, uma qualidade indizível que me arrepiou ainda mais.(LOVECRAFT, 2017, s/p)

A descrição do monstruoso retém aspectos de impureza e repulsão; em seguida é remetida a ela a terminologia eidolon. Se considerarmos que o uso remete à literatura grega antiga, sua característica de fusão é ressaltada, podendo evocar a aparição de um zumbi. A estranheza do ser também pode ser relacionada à criatura refletir alguns medos do imaginário coletivo, como a destruição de tudo o que era tido como verdade - os mortos não mais voltarão a este mundo.

Outro aspecto que merece relevo é a maturação do personagem marcada pela saída do campo para cidade. Deixa a área onde vivia, situada distante da cidade, e, conforme desbrava o exterior, se afasta de sua visão imatura de si e do mundo; quando chega ao castelo (civilização/cidade), o personagem passa à sua fase madura, o que reflete na consciência de sua condição e identidade. Esse processo acontece na confrontação da personagem com o monstro que lhe causou tanto horror - com o seu duplo -, seu próprio reflexo.

Nesse momento, "tudo o que deveria permanecer em segredo, oculto, [...] apareceu" (FREUD, 2010, p.337). O unheimlich, a partir desse momento, é posto de dentro para fora; o ser que não se 
conhece é também um estrangeiro, um estranho para si mesmo. Sem demora, o horror cósmico aparece pelo reconhecimento do duplo que, então, torna-se único. Vejamos o trecho:

Tive a súbita e agoniante noção da proximidade daquela coisa putrefata, cuja horrenda respiração oca eu quase imaginei poder ouvir. Semienlouquecido, descobri-me ainda capaz de lançar uma das mãos a frente para afastar a fétida aparição que tão perto impunha sua presença; foi quando em um cataclísmico segundo de pesadelo cósmico e acaso infernal meus dedos tocaram a garra apodrecida que o monstro estendia sob o arco dourado. Não gritei, mas todos os espectros diabólicos que cavalgavam o vento da noite urraram por mim, pois naquele mesmo segundo desabou sobre minha mente uma única e fugaz avalanche de lembranças capazes de aniquilar a alma. Soube naquele segundo tudo o que eu havia sido; minha memória foi além do pavoroso castelo com suas arvores, e reconheceu o edifício alterado em que eu naquele momento me encontrava. Reconheci, e foi o mais terrível de tudo, a abominação profana que me espiava, parada a minha frente, enquanto eu afastava meus dedos maculados pelo toque dos seus. (LOVECRAFT, 2017, p.303)

A partir desse momento, o personagem passa por uma transformação. Ao perceber o outro dentro de si, ele conhece sua imagem como forma exterior refletida no espelho. O confronto entre o eu imaginado e o eu exterior promove uma espécie de quebra da máscara, a perda da humanidade. A busca pelo conhecimento leva o narrador a encontrar a verdade sobre si, o que desencadeia a desestabilização e pede uma ressignificação, ou, melhor dizendo, uma adequação à realidade. 
Considerando a memória o local da eternidade, ao tentar retornar à sua condição inicial, o narrador percebe tal retorno como uma tarefa impossível - tanto física quanto mentalmente. Agora, a criatura se mantém livre das amarras do castelo, mas em uma nova prisão. O seu fardo é não estar no lugar desejado, deve se contentar em viver na escuridão de antes:

Num estado onírico, eu fugi daquele paço assombrado e maldito e corri veloz e silenciosamente à luz da lua. Quando retornei ao lugar de mármore no pátio da igreja e desci os degraus, descobri que o alçapão de pedra era irremovível; mas não lamentei, pois odiava o castelo antigo com todas as suas arvores. Hoje cavalgo com os zombeteiros e amigáveis espectros no vento noturno [...] Sei que a luz não é pra mim, exceto aquela que a lua projeta sobre as tumbas rochosas de Neb, nem qualquer alegria exceto os festins inomináveis de Nitokris, sob a Grande Pirâmide; embora em minha nova turbulência e liberdade eu quase acolha a amargura do exilio. Pois embora o nepente tenha me acalmado, sempre saberei que sou um intruso, um estranho neste século e entre aqueles que ainda são homens. (LOVECRAFT, 2017, p.303)

O unheimlich, assim, se verifica na forma do conto: é a configuração do narrador que escamoteia sua verdadeira natureza. O confronto entre o interno e o externo se dá de maneira intensa, deixando marcas até mesmo na primeira parte do conto. O estranhamento do personagem para com sua verdadeira natureza nunca é superado de maneira plena, posto que na conclusão ele se mantém ciente de sua condição de estrangeiro. Contudo, o autoconhecimento e a superação do recalque somente 
acontecem por meio do contato com o outro, com o estranho, com o unheimlich - e, dada a já mencionada inversão no ponto de vista, o outro, o estranho e o unheimlich somos também nós, os leitores.

\section{REFERÊNCIAS}

BACHELARD, Gaston (1978). A poética do espaço. Antônio da Costa Leal e Lídia do Valle Santos Leal (Trads.). São Paulo: Abril Cultural. Coleção Os pensadores. BORGES, Jorge Luis (1989). "El espejo". In: . Obras completas de Jorge Luis Borges. Vol.3. Buenos Aires: Emecé Editores.

CARROLL, Noel (1999). A filosofia do horror ou paradoxos do coração. Campinas, São Paulo: Papyrus.

FREUD, Sigmund (2010). "O inquietante." In: . Freud Obras Completas volume 14: História de uma neurose infantil ("O homem dos lobos"), Além do princípio do prazer e outros textos (1917-1920). Paulo César de Souza (Trad.). Companhia das letras.

LOVECRAFT, H. P. (1987). O horror sobrenatural na literatura. Francisco Alves. (2017) "O intruso". In: . Contos reunidos. Bruno Costa (Org.). Francisco Innocêncio (Trad.). São Paulo: Ex Machina.

POE, Edgar Allan (2007). "The masque of the red death". In: . The complete tales and poems. Nova York: Barnes and Noble. 